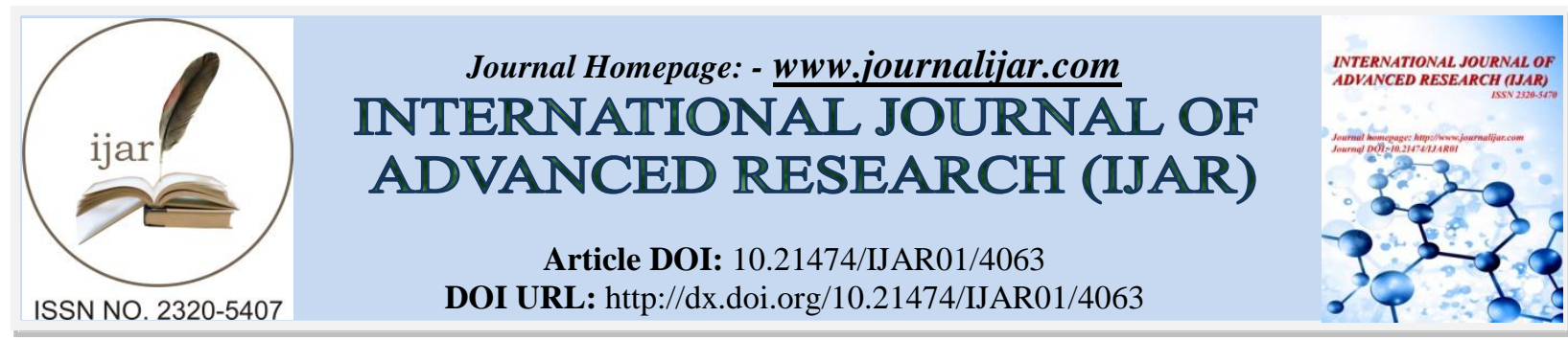

RESEARCH ARTICLE

\title{
ANDROID APP SOLUTION for FARMERS and BUYERS to SELL AND BUY PRODUCTS WITHOUT ANY BROKER INVOLVED.
}

\section{Dr. H. Lilly Beaulah ${ }^{1}$ and Mrs. Latha $\mathbf{P ~ S}^{2}$.}

1. Professor \& Head, Department of Computer science and Engineering, Mahendra College of Engineering,Salem.

2. Assistant professor, Department of Computer science and Engineering, Mahendra College of Engineering,Salem.

\section{Manuscript Info \\ Manuscript History}

Received: 21 February 2017

Final Accepted: 23 March 2017

Published: April 2017

\begin{abstract}
We say farmers are our backbone or the whole world is completely dependent on agriculture, because when there is no agriculture there is no food and harvesting, so farmers are not only backbones of some particular areas but they are the important race in our society. But as this category is lacking education in harvesting and failed in getting information on new techniques of harvesting to get more yields and using the same old method for harvesting, there are many issues increasing in front of them because as a farmer their main source of income is to sell the products they harvest but in the same way if they are unable to get enough earnings from that, then they seek government help and even if government helps them, without much knowledge again they fail to harvest valuable quantity of products and obviously their earnings will go low.

The farmers not only facing the issues in the sector of agriculture or crop harvesting but once they harvest again they face same old issue of selling the products to the buyers, here a new kind of people take their part to whom we can identify as mediators, these mediators take most of the earnings of farmers as well as buyers by cheating both and gain more money. This application helps farmers individually to grow better and it also helps to get valid information about how to yield more crops and the condition of soil as well as the type of seeds needs to harvest for the type of land they have, to grow more and get more profit out of it. The farmers can avoid to sell their products on mediators.
\end{abstract}

Copy Right, IJAR, 2017,. All rights reserved.

\section{Introduction:-}

In India farming is said to be prime job and one and only work to which Government provides many schemes, loans and subsidies on the bank loan to help farmers. If we consider any job to be completed successfully then we tends to know how to do it for to take success in that, a work without any proper ideas or plans is considered to be fail.

As we know our farmers are poor on an ratio if we consider but as if they harvest the food which is primary supplement for our health even though they are not that wealthy like other people, if we take close look what may be the issue then, there are many reasons we can find easily.

Corresponding Author:- Dr. H. Lilly Beaulah.

Address:- Professor \& Head, Department of Computer science and Engineering, Mahendra College of 
The reasons for the farmers failure to achieve earnings as well as good outcomes are many some of them are listed below.

$>$ The farmers of India in most of the regions are not aware of new techniques of harvesting and they are using the same old technique of harvesting that the reason of failure in getting the expected crops outcome.

$>$ The farmers of India is confused and lack of knowledge, when it comes to market rates and selling their products to buyers, here if a mediator involves for example if a farmer wants to sell his crops and searching for buyers most of the time the mediator involves in this and most of the money flows to the mediator rather than the farmers or buyers again the farmer got lost his most of the earnings by paying extra amount to the mediators so, even in this section farmer needs help and needs to be educated.

$>$ The farmers at the time of harvesting takes loan from the bank in the belief of rain and good earnings at the end but farmers fails to get what he thought of, this happens most of the time in India and in many regions farmers get suicide because of non-refund of bank loans and failure in their proper outcomes and earnings, even in this section we need to educate our farmers and need to guide them how to harvest and sell as well how to get the good money.

After looking at all the issues that farmers are having in today's life, so a new thought to help farmers by educating them with an easy medium the proposed idea that helps out and solves many issues of the farmer easily.

\section{Problem Statement:-}

The farmers are becoming weak, due to loss of crops lack of agricultural knowledge etc. farmers depends only on farming in most of the region. But in present condition farmers are facing many problems. So to overcome from his problem, farmer needs some support and guidance to cultivate land in a proper direction and some information on the new techniques of harvesting.

\section{Existing System:-}

The existing system is not providing solutions on agriculture and horticulture together and most of the applications have not included the complete solutions or information needed to the farmers that help them to get most of yields from their land and solutions on selling the products directly to the buyers.

The information on the pesticides and soil quality as well as the conditions of weather has to be checked earlier on websites which definitely not possible by all farmers and they needed something better solution than the old way and that will be easily taken care by the proposed application.

\section{Proposed System:-}

The proposed system provides all kind of help that a farmer needs to know about harvesting the crops, start to the end process is included in the proposed application where the farmers can easily get the information on soil condition and best way to irrigation process as well as the present year market value of the products and new techniques of harvesting the crops.

The proposed application helps in selling the products directly to the buyers without intervention of any third person (mediators) with the help of options present in application.

It cures all issues of existing system as it reaches everyone and can be accessible by every farmer. The application proposes new techniques of harvesting from many other successful farmers, It also includes image upload option where one can easily do.

\section{Advantage of Proposed System:-}

$>$ The application reaches to everyone easily.

$>$ The Farmers will get the information on cultivation of crops.

$>$ Farmers get educated easily with this application.

$>$ The Farmers has an option to upload the image of their crops and quote the amount for the product with the quantity they are having. By this option farmers can directly sell their product.

$>$ The Farmers can add the detail information on the new technique of cultivation.

$>$ The Farmers can query other Farmer regarding the new Technique of cultivation.

$>$ The Buyers can view the product details and market details. The Buyers can directly interact with farmers and can purchase the product.

$>$ This app helps to get more crops as well as it helps to get valuable amount of earnings. 


\section{System Design And Development:- \\ Development Method:-}

In the Proposed Project Waterfall Model is used as a development method. The reason behind this is it is simple, easy to understand, easy to manage as each and every step is having targeted task. The figure 5.1 shows the overview of waterfall model.

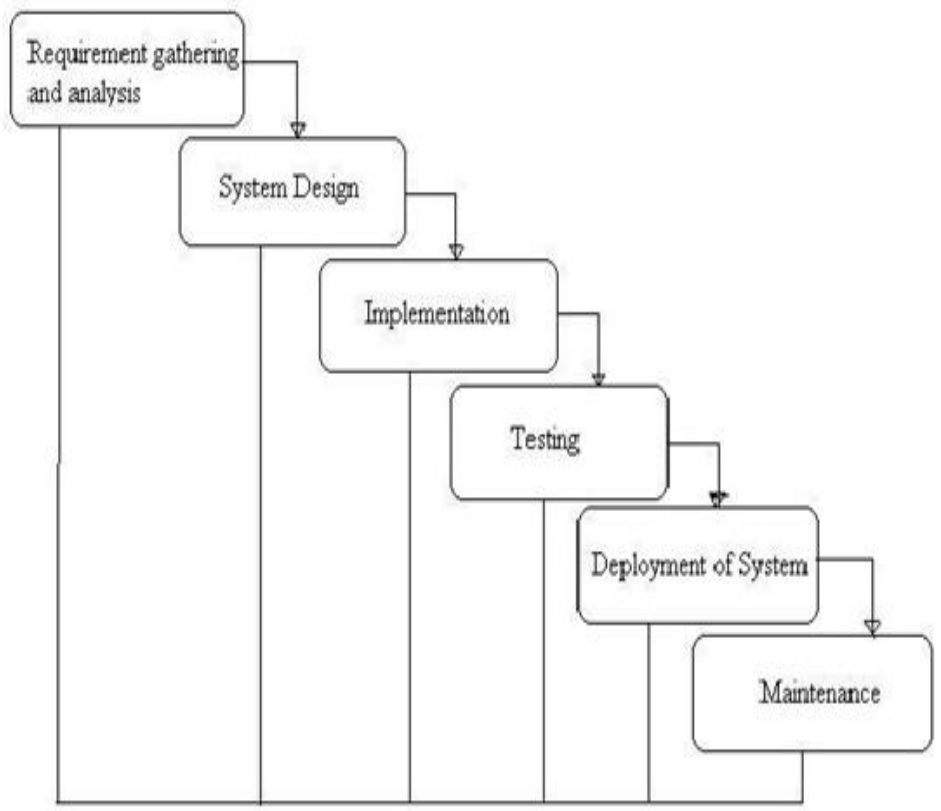

Figure 5.1:- Overview of model used

Modules of the project:-

$>$ Registration module

$>$ Login module

$>$ Farmer module

$>$ Buyer module

\section{Registration module:-}

The application welcome screen contains the login and new user option. Where the new farmer or the buyer can register to the application. Here in this module the options included are username, password, contact number and other useful informations depending on the farmer or buyer.

\section{Login Module:-}

The main window of the application displays the login screen and after successful login only it allows the user to enter for next section of options.

\section{Farmer Module:-}

Once the farmer successfully signed in to the application there are two options awaiting for the user these options are i) Agriculture and ii) Horticulture depending on the section the farmer needs to see the information or it may be the market value to sell the items and want to upload the information that he can do easily. All kind of valuable information the farmer can search and use for his future harvestings to get more yields in the agriculture field.

\section{Buyer Module:-}

In this module once buyer successfully signed in to the application buyers can search the required crops, want to buy from many listed farmers who have already placed information about their products and also can compare the prices, can take a good look on the quality of the product with the help of the images uploaded by the farmers.

As well as buyers can even check the market rate of the product this is placed every year of December month by the government and, that helps him to buy the product easily 


\section{Architecture of proposed system:-}

The architecture diagram of proposed application will give a brief idea about flow of the project and how the application works.

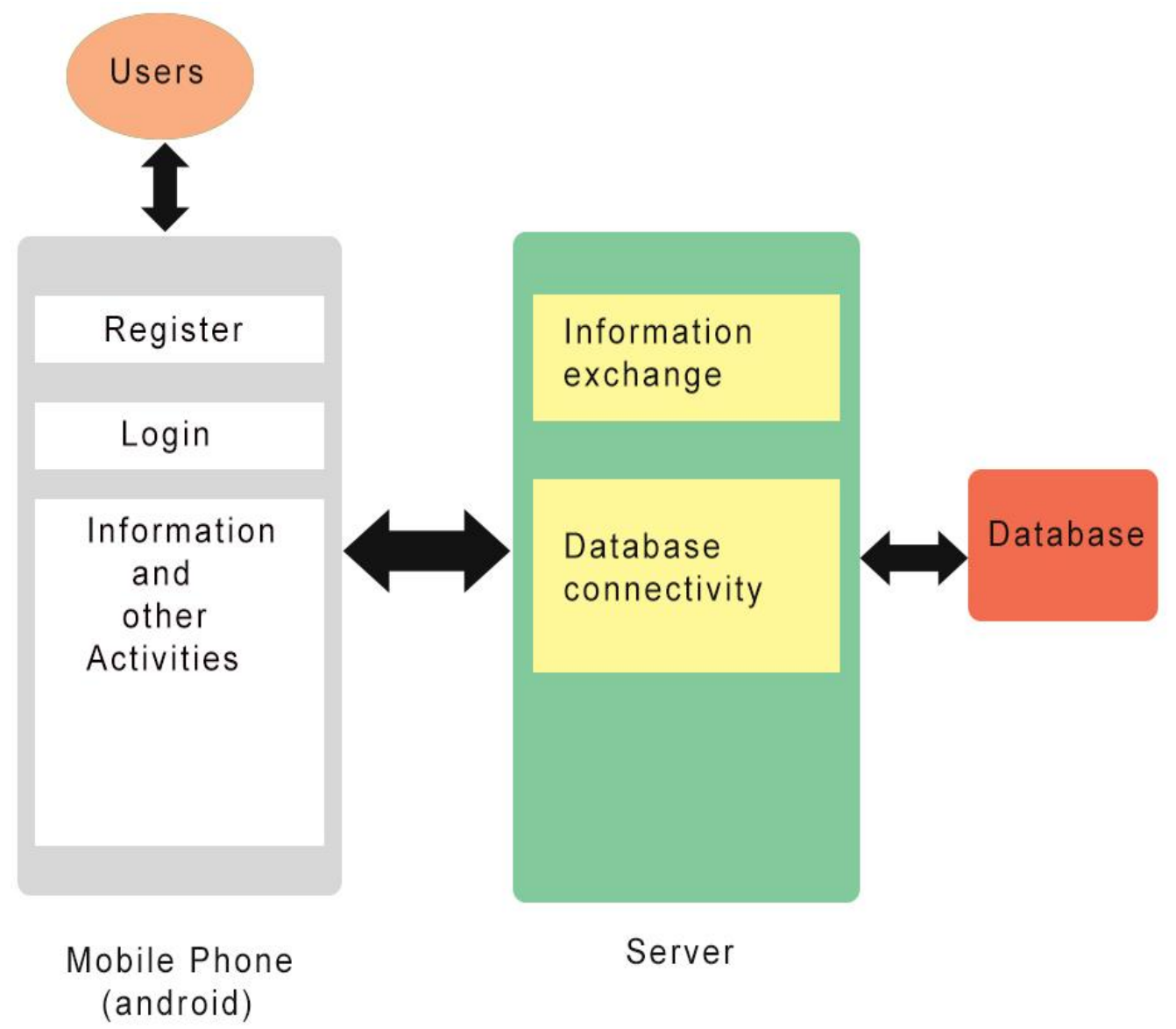

Fig 1:- Architecture design 
Registration Module data flow design:-

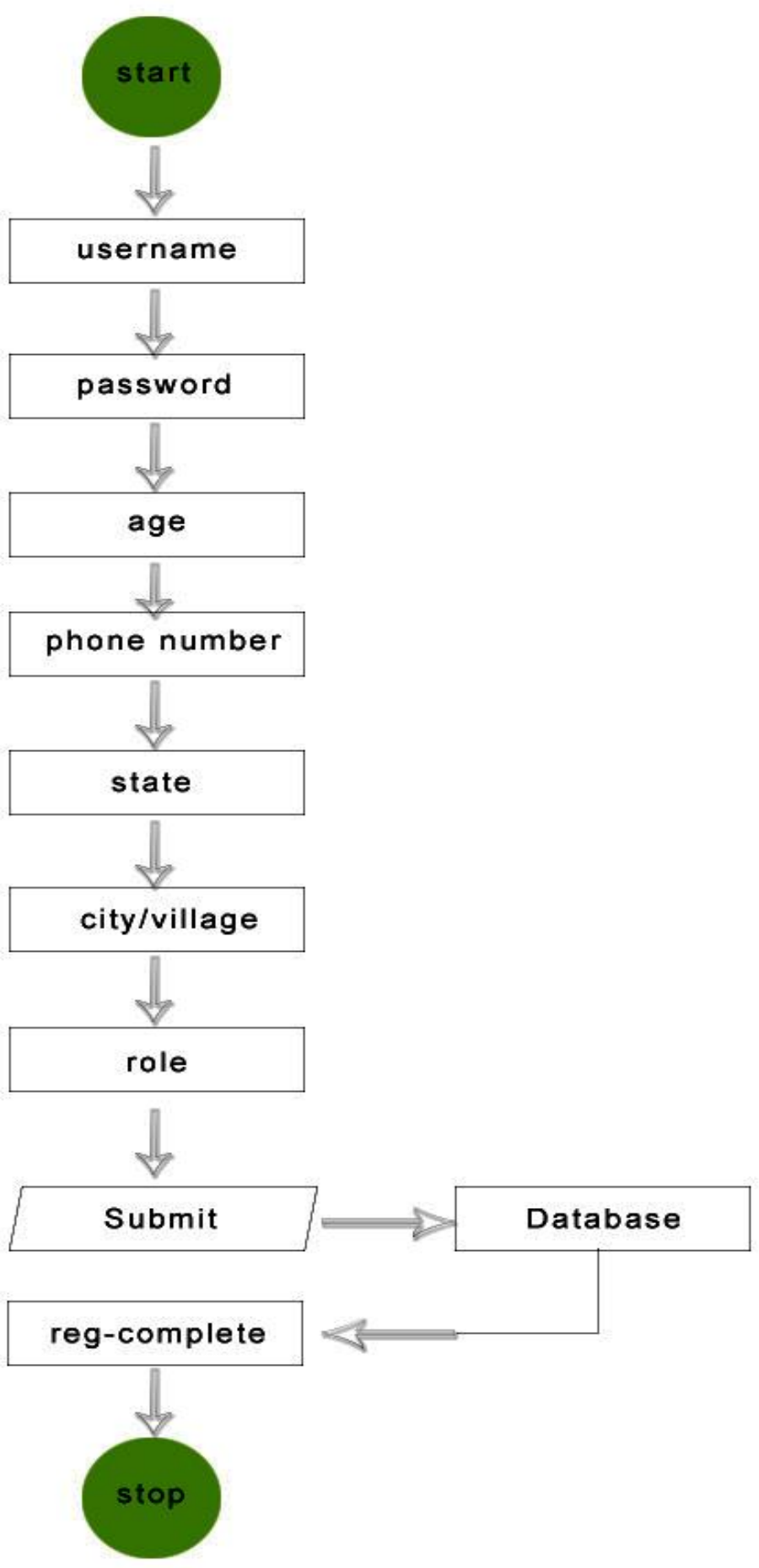

Fig. 2:- Dataflow design of registration module. 
Login Module dataflow Design:-

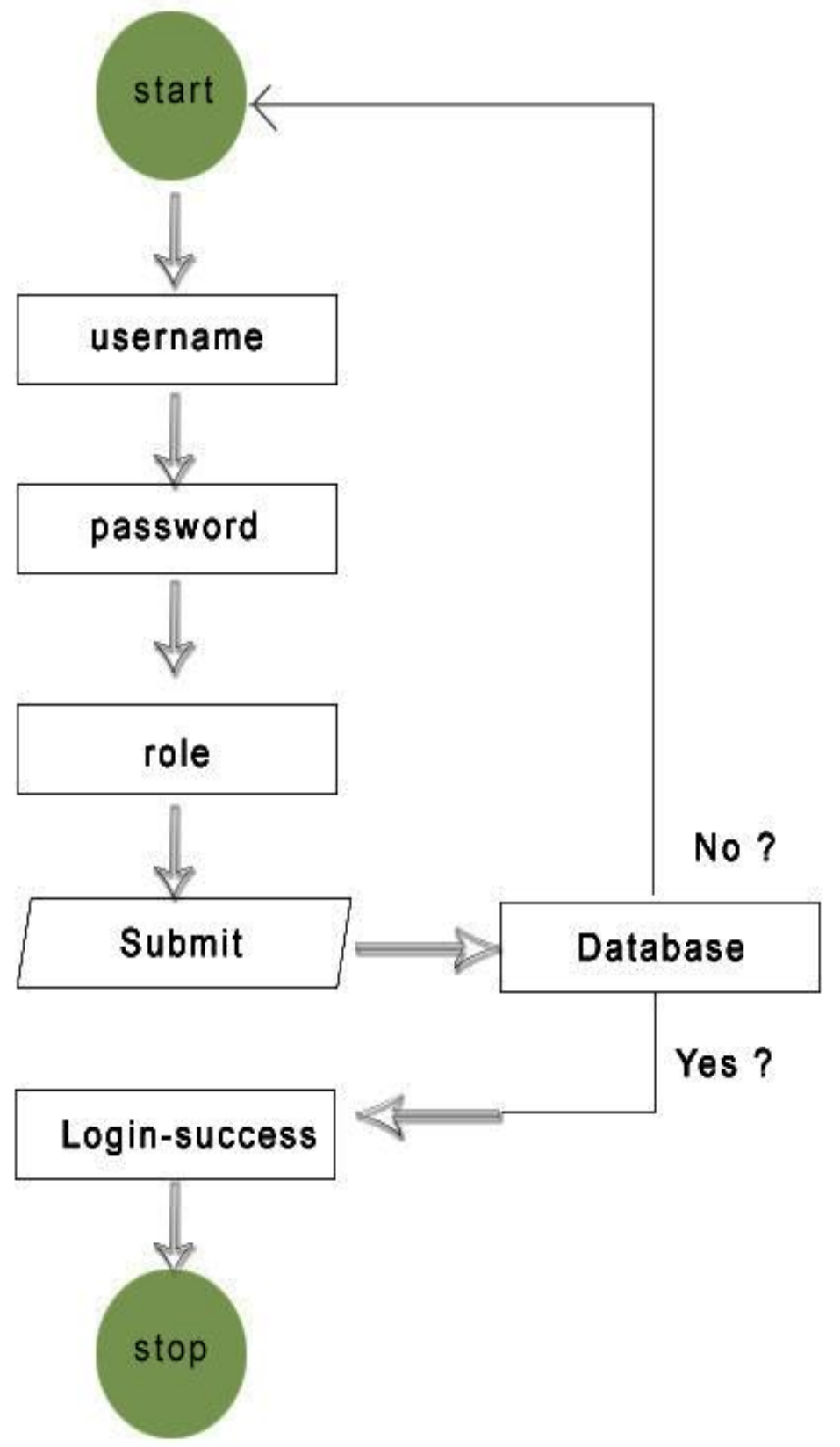

Fig 3: Login module design 


\section{Farmers Data flow Design:-}

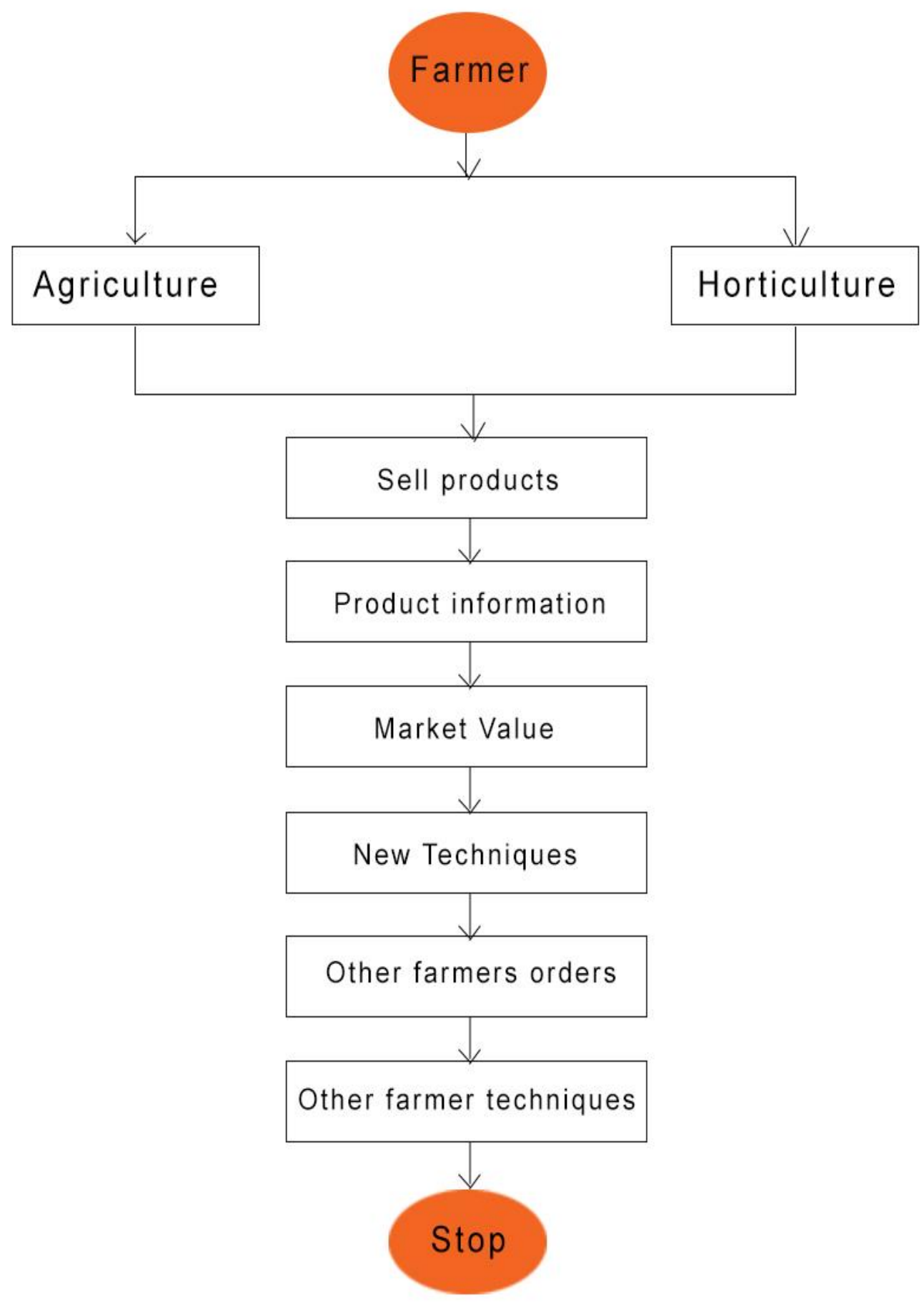

Fig 4:- Farmers Module dataflow Design. 


\section{Buyers Data flow Design:-}

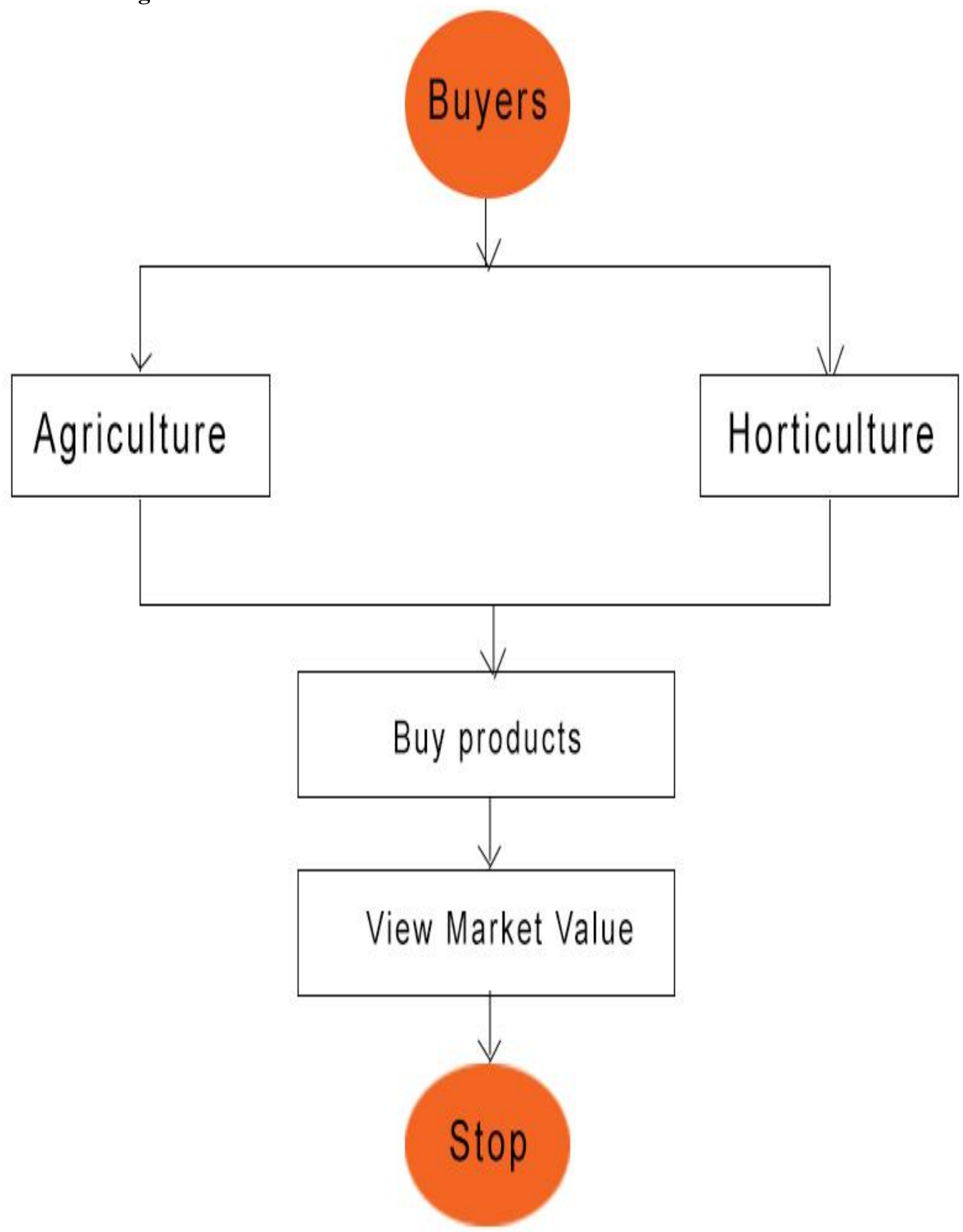

Fig. 5:- Buyers module dataflow design

\section{Application Source Files:-}

FarmerBuyerMainScreenActivity.java: The Main Screen of the Application will be in java class.

AndroidManifest.xml - Android application deployment descriptor.

BuyerBuyFarmerOrdersListScreenActivity.java: The java class contains the Farmers orders List to Buyer to buy the product.

- FarmerBuyerMarketValueProductScreenActivity.java: The java class has the Market value of the Agricultural and Horticultural Product. 


\section{Imports Files:-}

$>$ import android.support.v7.app.actionbaractivity: Support library appcompat.

$>$ import android. os. asynctask: AsyncTask enables proper and easy use of the UI thread.

$>$ import android.util.base64: Utilities for encoding and decoding the Base64 representation of binary data

\section{Conclusion:-}

Many applications have provided agriculture ideas and explain how to achieve well farming, every application proposes many different ideas that helped farmers. The application is an android application that reaches to many hands and it is merely helpful application that is having valid options like selling products directly to the buyers and getting the product information or information on how successfully harvest by looking at other successful farmers ideas.

As any farmer can share his idea using this application this is very helpful that inspires most of the farmers and lead them to use new farming techniques. Also the application uses the market value option that helps many farmers to accurate in fixing the product rate.

The application stops most of the mediator's activity with the option selling/buying directly to the farmer/buyer. The application is very helpful and solves most of the farmers issues as well as it is helpful in guiding them the best way on farming.

\section{Future Enhancement:-}

The Proposed Application can be improved by providing Information on

$>$ Plantation crops

$>$ Cash crops

$>$ Floriculture

$>$ Machinery.

\section{References:-}

1. https://www.sarkariyojna.co.in > Central Government

2. https://play.google.com/store/apps/details?id=com.criyagen\&hl=en

3. https://play.google.com/store/apps/details?id=com.rml.Activities

4. www.croplife.com/editorial/matt-hopkins/10-best-new-agriculture-apps-for-2015/

5. www.mobilefarmapps.com/

6. www.networkedindia.com/.../3-agri-apps-that-are-helping-farmers-buysell-produce-ef.

7. modernfarmer.com/2016/01/agriculture-apps-india/

8. mkisan.gov.in/downloadmobileapps.aspx

9. https://www.enterpriseinnovation.net/.../indias-farmers-turn-mobile-apps-1956219016

10. https://www.indiaagronet.com/Agriculture.../Agriculture-Information-Apps.html

11. www.orangemantra.com/.../indian-farmers-get-mobile-applications-to-ease-the-agricu...

12. https://www.youtube.com/watch?v=yhmq4Jshlbs

13. innovatefordigitalindia.intel.in/a-dream-to-transform-farming-with-technology.html

14. https://www.slideshare.net/arunkumarss/agricultural-apps-for-android-mobiles 